\title{
AVALIAÇÃO DA BIODEGRADABILIDADE ANAERÓBIA DE RESÍDUOS DA BOVINOCULTURA E DA SUINOCULTURA
}

\author{
LUCIANA M. MORAES ${ }^{1}$, DURVAL R. PAULA JÚNIOR ${ }^{2}$
}

RESUMO: A biodegradabilidade de dejetos da bovinocultura e da suinocultura foi avaliada por meio de metodologia simplificada que permitiu a verificação da aplicabilidade de processos anaeróbios. Os ensaios foram realizados com reatores em batelada, com lodos granulados de três procedências: reator UASB tratando efluente de bovinocultura, reator UASB tratando efluente de suinocultura e reator UASB tratando efluente de abatedouro de aves. Os ensaios (1) - efluente de bovinocultura e lodo de abatedouro de aves não-adaptado; (2) - efluente de suinocultura e lodo de abatedouro de aves nãoadaptado; (3) - efluente de bovinocultura e lodo de abatedouro de aves adaptado; (4) - efluente de suinocultura e lodo de abatedouro de aves adaptado; (5) - efluente de bovinocultura e lodo de bovinocultura, e (6) - efluente de suinocultura e lodo de suinocultura realizados em "Shaker", em temperatura de $35^{\circ} \mathrm{C}$, sob agitação a $150 \mathrm{rpm}$, por 5 minutos a cada 1 hora. Foi utilizada uma relação de substrato:biomassa igual a 0,5. Foram testados modelos cinéticos do tipo Monod, Ordem Zero, Primeira e Segunda Ordens e verificou-se que o modelo de Primeira Ordem foi o que melhor se ajustou para os seis ensaios realizados. A constante de velocidade de Primeira Ordem $\left(\mathrm{k}_{1}\right)$ foi estimada para os ensaios $1 ; 2 ; 3 ; 4 ; 5$ e 6 , resultando $2,51 \times 10^{-2} ; 2,49 \times 10^{-2} ; 1,90 \times 10^{-2} ; 3,09 \times 10^{-2} ; 2,54 \times 10^{-2}$, e $4,09 \times 10^{-2} \mathrm{~h}^{-1}$, respectivamente.

PALAVRAS-CHAVE: processo anaeróbio, suinocultura, bovinocultura.

\section{ANAEROBIC BIODEGRADABILITY OF WASTEWATER FROM DAIRY AND SWINE}

SUMMARY: The biodegradability of animal wastes production was evaluated through a simplified methodology that allowed the verification of the applicability of anaerobic processes. The experiments were performed in bath reactors, with granular sludge of three origins: UASB reactor treating dairy effluent, UASB reactor treating swine effluent and UASB reactor treating effluent of slaughterhouse of poultry. The experiments (1) - dairy effluent and poultry slaughterhouse non-adapted sludge; (2) swine effluent and poultry slaughterhouse non-adapted sludge; (3) - dairy effluent and poultry slaughterhouse adapted sludge; (4) - swine effluent and poultry slaughterhouse adapted sludge; (5) dairy effluent and dairy sludge, and (6) - swine effluent and swine sludge were performed in Incubator Shaker, at a temperature of $35^{\circ} \mathrm{C}$, under agitation at a $150 \mathrm{rpm}$, for 5 minutes, every 1 hour. A substrat:biomass relationship of 0.5 was used. Kinetic models of Monod, Zero Order, First and Second Order were tested and it was verified that the First Order model provided the best adjustment. The apparent First Order kinetic parameter $\left(\mathrm{k}_{1}\right)$ was estimated for the experiments $1 ; 2 ; 3 ; 4 ; 5$, and 6 , as $2.51 \times 10^{-2} ; 2.49 \times 10^{-2} ; 1.90 \times 10^{-2} ; 3.09 \times 10^{-2} ; 2.54 \times 10^{-2} ; 4.09 \times 10^{-2} \mathrm{~h}^{-1}$, respectively.

KEYWORDS: anaerobic process, dairy wastes, swine wastes.

\footnotetext{
${ }^{1}$ Zootecnista, Mestre em Engenharia Agrícola, aluna do Programa de Pós-Graduação, nível de Doutorado na Faculdade de Engenharia Agrícola, FEAGRI/UNICAMP, Campinas - SP, Fone: (0XX16) 272 4649, e-mail: lummoraes@ hotmail.com

${ }^{2}$ Professor Associado, Faculdade de Engenharia Agrícola, FEAGRI/UNICAMP, Campinas - SP.

Recebido pelo Conselho Editorial em: 6-11-2000

Aprovado pelo Conselho Editorial em: 5-5-2004
}

Eng. Agríc., Jaboticabal, v.24, n.2, p.445-454, maio/ago. 2004 


\section{INTRODUÇÃO}

De acordo com o Censo Agropecuário do Instituto Brasileiro de Geografia e Estatística (IBGE, 1997), em 1996, o Brasil possuía um rebanho de 928.679 .511 animais, dos quais, 16,48\% eram bovinos e 2,99\% eram suínos. Um dos principais problemas dos "Sistemas Intensivos de Criação Animal" é a grande quantidade de resíduos produzidos diariamente, devido à elevada concentração de animais, em pequenas extensões de terra.

Esses resíduos constituem-se de: dejetos (urina + fezes), material usado nas camas, água, produtos utilizados na limpeza, restos de animais (pêlos e células mortas), etc. Na bovinocultura de leite, o consumo médio de água, por animal, utilizado durante a higienização das instalações, varia de $10 \mathrm{~L} \mathrm{dia}^{-1}$ (WOLTERS \& BOEREKAMP, 1994) a $100 \mathrm{~L} \mathrm{dia}^{-1}$ (BUENO, 1986). Na suinocultura, esse consumo varia de 3,5 $\mathrm{L} \mathrm{dia}^{-1}$ (KONZEN, 1983) a 56,8 $\mathrm{L} \mathrm{dia}^{-1}$ (ZHANG \& DAGUE, 1995).

$\mathrm{Na}$ maior parte das vezes, esses resíduos são mal manejados, constituindo fonte de poluição do meio ambiente. Assim, estudos dos problemas ambientais relacionados ao tratamento e disposição dos dejetos gerados tornam-se urgentes.

O interesse pelo tratamento anaeróbio, de resíduos líquidos e sólidos provenientes da agropecuária e da agroindústria, tem aumentado nos últimos anos, por apresentar vantagens significativas quando comparado aos processos comumente utilizados de tratamento aeróbio de águas residuárias, ou aos processos convencionais de compostagem aeróbia de resíduos orgânicos sólidos. De acordo com PAULA JÚNIOR (1994), os benefícios apresentados pelo tratamento anaeróbio são: ausência de equipamentos sofisticados, menor consumo de energia, baixa produção de lodo a ser disposto e produção de metano, utilizável energeticamente.

Embora a experiência prática com o tratamento anaeróbio de efluentes líquidos seja ainda recente, o potencial de aplicabilidade do processo pode ser avaliado a partir do conhecimento de poucas características do despejo a ser tratado. Uma avaliação preliminar dessas características auxiliará na escolha do processo de tratamento mais adequado, permitindo, dessa forma, estimativas de produção de sólidos biológicos, de requisitos de nutrientes, de produção de metano, etc.

A caracterização dos dejetos, por meio de testes de biodegradabilidade, é de fundamental importância, uma vez que os dejetos apresentam grande variabilidade quanto à qualidade, quantidade, Demanda Química de Oxigênio (DQO) e presença de compostos orgânicos refratários. Acrescentamse, ainda, outras características importantes ao tratamento anaeróbio, notadamente: $\mathrm{pH}$, alcalinidade, nutrientes inorgânicos, temperatura e a eventual presença de compostos potencialmente tóxicos.

A biodegradabilidade de substratos pode ser relacionada aos valores do parâmetro cinético $\mathrm{k}_{1}$, denominado constante de velocidade para reação de Primeira Ordem, que mede a velocidade de uma reação em condições específicas e pode ser definido como a variação da concentração de um reagente ou produto na unidade de tempo, em uma reação na qual todos os reagentes se encontram em concentrações unitárias, desde que as mesmas condições experimentais sejam mantidas. Assim, quanto maior for o valor da constante, mais biodegradável será o substrato.

Os parâmetros cinéticos podem ser estimados utilizando as técnicas de Diferenciação e Integração de modelos reportados por SILVEIRA (1989), apresentados a seguir.

A equação cinética que representa o modelo de Primeira Ordem é expressa como:

$$
(-\mathrm{r})=\frac{\mathrm{dC}}{\mathrm{dt}}=\mathrm{k}_{1} \mathrm{C}
$$

em que,

$\mathrm{r}$ - velocidade de reação, $\mathrm{M} \mathrm{L}^{-3} \mathrm{~T}^{-1}$

$\mathrm{C}$ - concentração do reagente, $\mathrm{M} \mathrm{L}^{-3}$;

$\mathrm{t}$ - tempo, e

$\mathrm{k}_{1}$ - constante de velocidade para reação de Primeira Ordem, $\mathrm{T}^{-1}$. 
Nessa expressão, $\mathrm{k}_{1}$ é a constante de velocidade para a Reação de Primeira Ordem. Considerando uma concentração inicial $\mathrm{C}_{0}$, em um tempo t igual a $\mathrm{t}_{0}$, a eq.(1) pode ser integrada entre esses limites.

$$
\int_{C_{0}}^{C} \frac{d C}{C}=-k_{1} \int_{t_{0}}^{t} d t
$$

A expressão integrada expressa em termos de concentração pode ser escrita como:

$$
\ln \left(\frac{\mathrm{C}}{\mathrm{C}_{0}}\right)=-\mathrm{k}_{1}\left(\mathrm{t}-\mathrm{t}_{0}\right)
$$

$\mathrm{Ou}$

$$
\mathrm{C}=\mathrm{C}_{0} \times \mathrm{e}^{-\mathrm{k}_{1}\left(\mathrm{t}-\mathrm{t}_{0}\right)}
$$

A eq.(4) indica que a concentração, durante uma reação química, que segue cinética de Primeira Ordem, varia exponencialmente com o tempo. Assim, a partir da eq.(3), podemos representar graficamente $-\ln \left(\mathrm{C} / \mathrm{C}_{0}\right)$ em função do tempo, conforme apresentado na Figura 1, e obter o valor da constante de velocidade, $\mathrm{k}_{1}$, através da eq.(5).

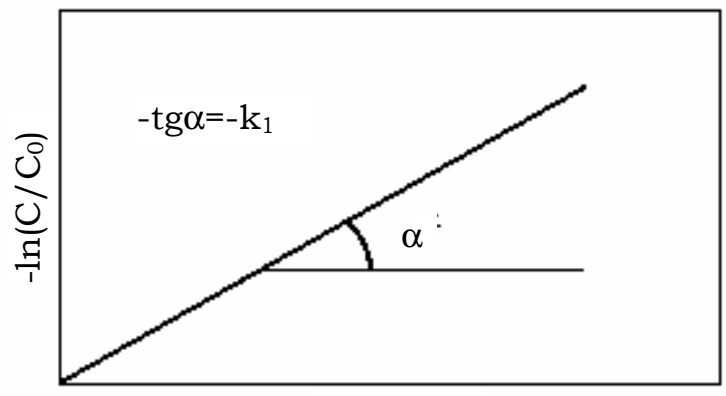

Tempo (t)

FIGURA 1. Representação gráfica da variação de $-\ln \left(\mathrm{C} / \mathrm{C}_{0}\right)$ com o tempo, para reação de Primeira Ordem.

$$
-\mathrm{k}_{1}=\operatorname{tg} \alpha
$$

O conhecimento da cinética das reações bioquímicas constitui-se em importante fator para o desenvolvimento da Tecnologia Anaeróbia, pois, além de os dados cinéticos fornecerem informações sobre o crescimento e utilização do substrato por diversas culturas, são úteis para a análise do sistema de tratamento e para o aumento de escala dos reatores. Dessa forma, os parâmetros cinéticos e operacionais podem ser equacionados para a verificação das relações existentes entre tais parâmetros e, conseqüentemente, da influência da cinética sobre a operação.

O objetivo deste trabalho foi avaliar a biodegradabilidade anaeróbia de dejetos oriundos da atividade zootécnica, por meio da estimativa da taxa de utilização de substrato, de forma a promover o maior conhecimento da cinética de sua biodegradação.

\section{MATERIAL E MÉTODOS}

Este trabalho foi realizado no Laboratório de Saneamento da Faculdade de Engenharia Agrícola da Universidade Estadual de Campinas - FEAGRI/UNICAMP, durante os anos de 1998 e 1999. 
Os ensaios de avaliação da biodegradabilidade anaeróbia foram realizados em mesa rotativa incubadora "Shaker", da marca Marconi, apresentados na Figura 2(a).

Nos ensaios, foram utilizados lodos granulados de três origens diferentes, adaptados ou não, compondo os ensaios com substratos oriundos de diferentes tipos de dejetos da produção zootécnica, conforme Tabela 1.

TABELA 1. Ensaios realizados.

\begin{tabular}{cll}
\hline Ensaios & Substrato (Água Residuária) & \multicolumn{1}{c}{ Lodo de Inóculo } \\
\hline 1 & Bovinocultura & Abatedouro de aves não-adaptado \\
2 & Suinocultura & Abatedouro de aves não-adaptado \\
3 & Bovinocultura & Abatedouro de aves adaptado \\
4 & Suinocultura & Abatedouro de aves adaptado \\
5 & Bovinocultura & Bovinocultura \\
6 & Suinocultura & Suinocultura \\
\hline
\end{tabular}

O lodo proveniente do reator do abatedouro de aves foi adaptado, com os substratos da bovinocultura e da suinocultura, a concentrações crescentes de DQO, por um período de 60 dias.

A caracterização inicial dos substratos (águas residuárias) e dos lodos de inóculo utilizados está apresentada nas Tabelas 2 e 3. As determinações de pH, DQO, Sólidos Suspensos Totais (SST), Sólidos Suspensos Voláteis (SSV), Sólidos Suspensos Fixos (SSF), Nitrogênio Total e Nitrogênio Amoniacal foram realizadas de acordo com o Standard Methods for the Examination of Water and Wastewater (AWWA, 1998). A análise de Ácidos Voláteis (AV) foi efetuada utilizando metodologia proposta por DILLALO \& ALBERTSON (1961), enquanto a de Alcalinidade Total (AT) foi efetuada utilizando metodologia proposta por RIPLEY et al. (1986).

TABELA 2. Caracterização inicial das águas residuárias, após centrifugação, utilizadas como substrato.

\begin{tabular}{|c|c|c|c|}
\hline \multirow{2}{*}{ Parâmetros } & \multirow{2}{*}{ Unidade } & \multicolumn{2}{|c|}{ Água Residuária } \\
\hline & & Bovinocultura & Suinocultura \\
\hline $\mathrm{pH}$ & - & 5,4 & 6,8 \\
\hline DQO & $\mathrm{mg} \mathrm{L}^{-1}$ & 1.520 & 2.183 \\
\hline Alcalinidade Total $\left(\mathrm{CaCO}_{3}\right)$ & $\mathrm{mg} \mathrm{L}^{-1}$ & 151 & 441 \\
\hline Ácidos Voláteis Totais & $\mathrm{mg} \mathrm{L}^{-1}$ & 265 & 175 \\
\hline Sólidos Suspensos Totais & $\mathrm{mg} \mathrm{L}^{-1}$ & 350 & 750 \\
\hline Sólidos Suspensos Fixos & $\mathrm{mg} \mathrm{L}^{-1}$ & 0 & 150 \\
\hline Sólidos Suspensos Voláteis & $\mathrm{mg} \mathrm{L}^{-1}$ & 350 & 600 \\
\hline Nitrogênio Total - Kjeldahl & $\mathrm{mg} \mathrm{L}^{-1}$ & 40 & 180 \\
\hline Nitrogênio Amoniacal & $\mathrm{mg} \mathrm{L}^{-1}$ & 28 & 164 \\
\hline
\end{tabular}

TABELA 3. Caracterização inicial dos lodos de inóculo.

\begin{tabular}{lcccc}
\hline \multirow{2}{*}{ Parâmetros } & \multirow{2}{*}{ Unidade } & \multicolumn{3}{c}{ Lodo de Inóculo } \\
\cline { 3 - 5 } & & Abatedouro de Aves & Bovinocultura & Suinocultura \\
\hline Sólidos Totais & $\mathrm{mg} \mathrm{L}^{-1}$ & 6.090 & 6.220 & 6.690 \\
Sólidos Totais Fixos & $\mathrm{mg} \mathrm{L}^{-1}$ & 1.210 & 1.150 & 1.230 \\
Sólidos Totais Voláteis & $\mathrm{mg} \mathrm{L}^{-1}$ & 4.880 & 5.070 & 5.460 \\
\hline
\end{tabular}


Após a caracterização dos substratos (águas residuárias), em termos de DQO, e dos lodos, em termos de Sólidos Totais Voláteis (STV), calcularam-se as quantidades de água residuária e lodo para cada reator, de forma a estabelecer a relação substrato/biomassa em torno de 0,5. A relação substrato/biomassa foi calculada por meio da eq.(6):

$$
\frac{\mathrm{S}_{0}}{\mathrm{X}_{0}}=0,5
$$

em que

$\mathrm{S}_{0}$ - concentração inicial de substrato, $\mathrm{mg} \mathrm{DQO} \mathrm{L}^{-1}$, e

$\mathrm{X}_{0}$ - concentração inicial de microrganismos, $\mathrm{mg} \mathrm{STV} \mathrm{L}^{-1}$.

Para a operação dos reatores anaeróbios, em sistema batelada, foram utilizados frascos de $350 \mathrm{~mL}$, conforme ilustrado na Figura 2(b). Cada experimento foi composto por dez frascos, sendo cada um deles preenchido com uma quantidade de lodo e de substrato, de forma a proporcionar a relação substrato/biomassa preestabelecida $(0,5)$, no início do teste. Ao longo do experimento, cada um dos frascos foi gradativamente sendo utilizado nas amostragens.
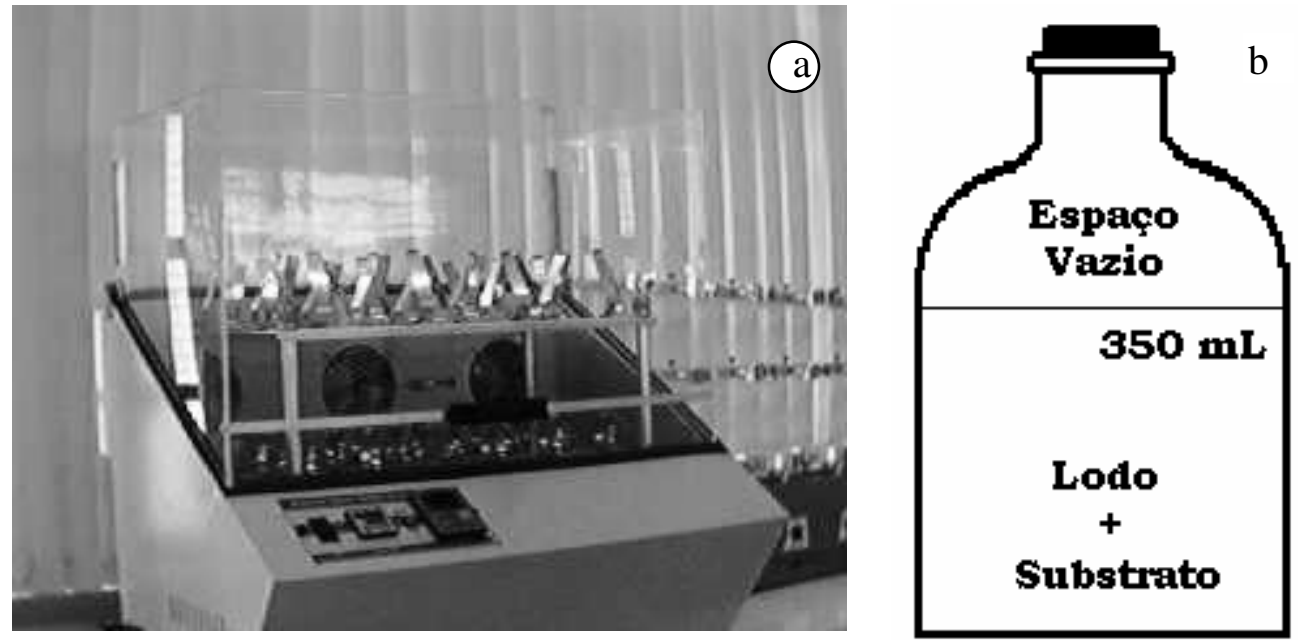

FIGURA 2. "Shaker” Marconi (a) e esquema geral dos reatores utilizados (b).

Os recipientes foram vedados e colocados no "Shaker". Durante os ensaios, a temperatura foi mantida em $35^{\circ} \mathrm{C}$, a agitação foi ajustada a $150 \mathrm{rpm}$ e realizada durante 5 minutos a cada 1 hora. No decorrer do experimento, foram retirados nove dos dez frascos que compunham o ensaio, um a um, em intervalos determinados que variaram de acordo com o substrato analisado. Amostras do sobrenadante foram coletadas para análise da DQO centrifugada. Os ensaios realizados com efluente de bovinocultura e efluente de suinocultura tiveram, respectivamente, a duração de 24 e 15 horas.

Para a obtenção de uma melhor expressão que representasse o comportamento do sistema estudado, foram realizados estudos de correlação e regressão matemática dos dados com auxílio de ferramentas do programa computacional Microsoft Excel 97. Foram estudados os modelos cinéticos do tipo Monod, de Ordem Zero, Primeira e Segunda Ordens.

Como um grande número de bactérias anaeróbias estão envolvidas na transformação da matéria orgânica complexa em moléculas mais simples, mas alguns fungos e protozoários também podem estar presentes durante esse processo, no início de cada experimento, foi realizada uma caracterização microbiológica em amostras de lodo (lodo bruto e grânulos individualmente) por meio de microscopia de luz e fluorescência, visando a identificar os tipos de microrganismos presentes. 


\section{RESULTADOS E DISCUSSÃO}

Na Figura 3, apresentam-se as curvas de monitoramento dos valores médios de DQO (mg L $\left.{ }^{-1}\right)$ em função do tempo (horas), em cada um dos ensaios realizados.
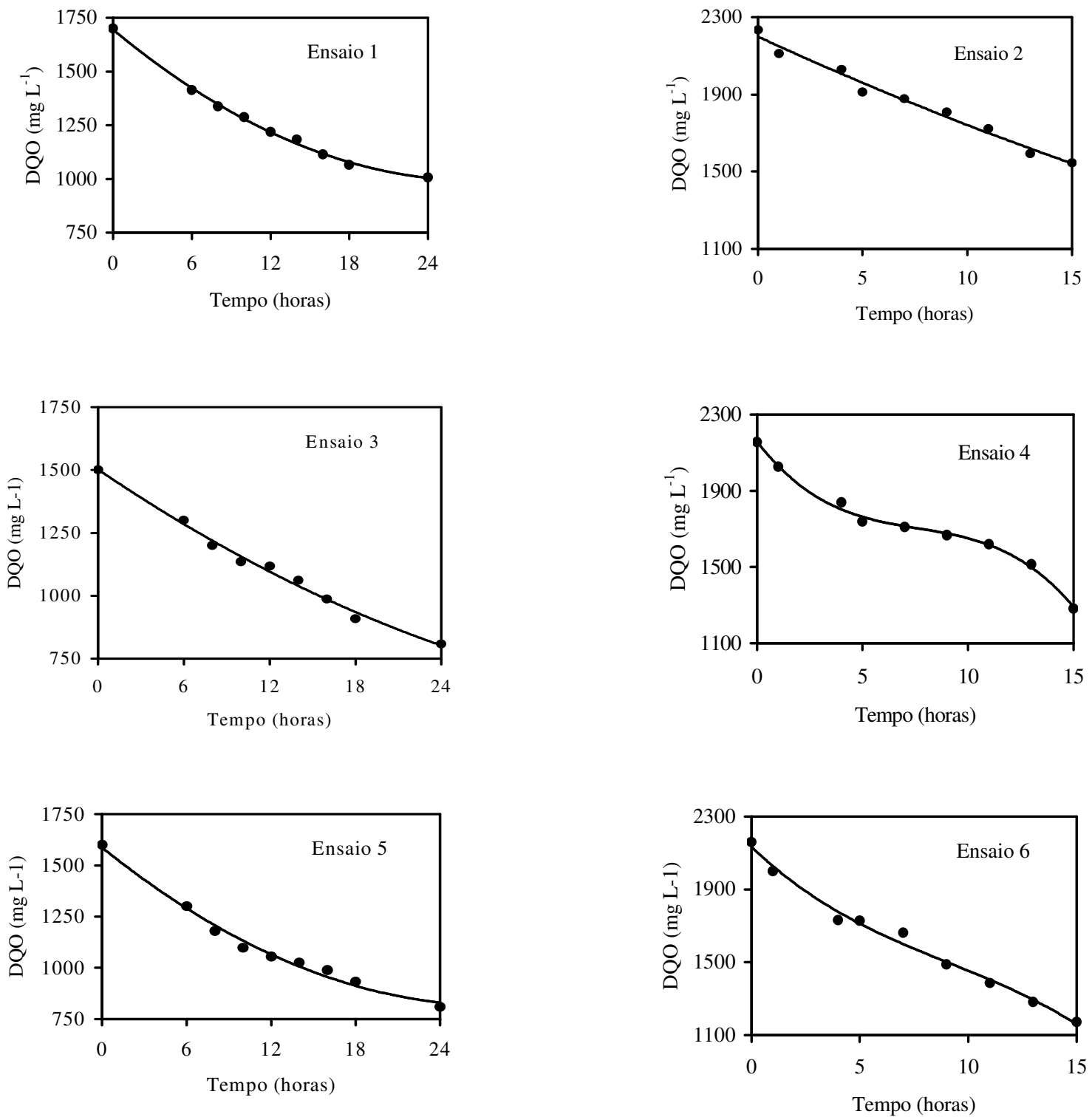

FIGURA 3. Variações dos valores médios de DQO $\left(\mathrm{mg} \mathrm{L}^{-1}\right)$, em função do tempo (horas), para cada um dos ensaios realizados.

Os Parâmetros Cinéticos $\left(\mathrm{k}_{1}\right)$ de cada um dos ensaios de biodegradabilidade realizados, para o modelo de Primeira Ordem, que permitiram o melhor ajuste, foram calculados a partir da evolução temporal do consumo de substrato, em termos de concentração de DQO, e estão apresentados na Tabela 4. Os resultados detalhados de operação dos ensaios realizados e da determinação dos parâmetros cinéticos foram reportados por MORAES (2000).

O parâmetro cinético aparente estimado $\left(\mathrm{k}_{1}\right)$, denominado constante de velocidade para reação de Primeira Ordem, mede a velocidade de uma reação em condições específicas e pode ser definido como a variação da concentração de um reagente ou produto na unidade de tempo, em uma reação na qual todos os reagentes se encontram em concentrações unitárias. A unidade da constante $\mathrm{k}_{1}$ depende da 
ordem global da equação e, nesse caso, como foram obtidas equações de Primeira Ordem, sua unidade é $h^{-1}$.

TABELA 4. Parâmetros Cinéticos de Primeira Ordem estimados para os ensaios realizados.

\begin{tabular}{clcc}
\hline \multirow{2}{*}{$\mathrm{N}^{\circ}$} & \multicolumn{1}{c}{ Ensaios } & \multicolumn{2}{c}{$\mathrm{k}_{1}\left(\mathrm{~h}^{-1}\right)$} \\
\cline { 3 - 4 } & & Não-Adaptado & Adaptado \\
\hline 1 e 3 & Efluente de Bovinocultura e Lodo de Abatedouro de Aves & $2,51 \times 10^{-2}$ & $1,90 \times 10^{-2}$ \\
2 e 4 & Efluente de Suinocultura e Lodo de Abatedouro de Aves & $2,49 \times 10^{-2}$ & $3,09 \times 10^{-2}$ \\
5 & Efluente de Bovinocultura e Lodo de Bovinocultura & - & $2,54 \times 10^{-2}$ \\
6 & Efluente de Suinocultura e Lodo de Suinocultura & - & $4,09 \times 10^{-2}$ \\
\hline
\end{tabular}

A biodegradabilidade de substratos pode ser relacionada aos valores do parâmetro $\mathrm{k}_{1}$, desde que as mesmas condições experimentais sejam mantidas. Assim, quanto maior o valor da constante, mais biodegradável o substrato.

$\mathrm{Na}$ avaliação do efluente de bovinocultura como substrato, ensaios $1 ; 3$ e 5 , os valores de $\mathrm{k}_{1}$ obtidos foram $2,51 \times 10^{-2} ; 1,90 \times 10^{-2}$ e $2,54 \times 10^{-2} \mathrm{~h}^{-1}$, respectivamente. Pode-se observar que, tanto para o ensaio realizado com o lodo de abatedouro de aves não-adaptado (ensaio 1), como para o ensaio com o lodo de bovinocultura (ensaio 5), foram obtidos valores muito próximos de $\mathrm{k}_{1}$, indicando uma remoção de substrato muito semelhante. No ensaio realizado após a adaptação do lodo de abatedouro de aves (ensaio 3), o valor de $\mathrm{k}_{1}$ foi inferior aos obtidos nos demais ensaios com o efluente de bovinocultura $\left(1,90 \times 10^{-2} \mathrm{~h}^{-1}\right)$, indicando que, nesse caso, o processo de adaptação utilizado não foi satisfatório.

$\mathrm{Na}$ avaliação do efluente de suinocultura como substrato, ensaios 2 ; 4 e 6 , os valores de $\mathrm{k}_{1}$

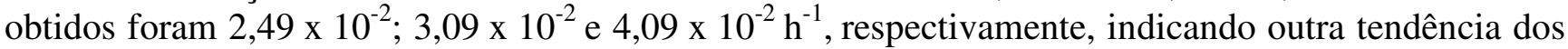
valores. $\mathrm{O}$ valor obtido no ensaio com o lodo de abatedouro de aves adaptado (ensaio 4) superou em $24 \%$ o obtido no ensaio com o mesmo lodo não-adaptado (ensaio 2), indicando que o processo de adaptação, nesse caso, foi satisfatório. No ensaio com lodo de suinocultura (ensaio 6), o valor de $\mathrm{k}_{1}$ foi o maior obtido $\left(\mathrm{k}_{1}=4,09 \times 10^{-2} \mathrm{~h}^{-1}\right)$.

Os valores de $\mathrm{k}_{1}$ obtidos para os modelos de Primeira Ordem, em todos os ensaios deste trabalho, foram da mesma ordem de grandeza que o valor de $\mathrm{k}_{1}$ obtido por VIEIRA (1996), para o modelo cinético de Primeira Ordem, $\mathrm{k}_{1}=6,74 \times 10^{-2} \mathrm{~h}^{-1}$, para degradação de glicose em sistemas com células imobilizadas.

A análise microscópica dos lodos realizada com o objetivo de caracterizar a biomassa presente em cada ensaio está apresentada na Figura 4.

Distintas morfologias foram observadas durante a microscopia por contraste de fases e por fluorescência (Figura 4), sendo que, em todos os lodos, os microrganismos predominantes foram os bacilos retos $(\boldsymbol{e})$ e curvos $(\boldsymbol{d})$, além dos cocos $(\boldsymbol{g}$ e $\boldsymbol{j})$. Após a adaptação do lodo de abatedouro de aves com efluente de bovinocultura, pôde-se observar a ocorrência de estruturas celulares danificadas $(\boldsymbol{k})$.

Foi possível constatar, no desenvolvimento do experimento, que a padronização do procedimento de adaptação não é recomendável, uma vez que não se observou o mesmo comportamento em lodos adaptados com procedimentos idênticos. Na adaptação do lodo de abatedouro de aves com efluente de bovinocultura, observou-se uma diminuição da constante $\mathrm{k}_{1}$, em relação ao valor obtido para o mesmo lodo não-adaptado, enquanto, na adaptação do lodo de abatedouro de aves com efluente de suinocultura, se observou um aumento da constante $\mathrm{k}_{1}$ em relação ao valor obtido para o mesmo lodo não-adaptado. Microscopicamente, pode-se observar no lodo de abatedouro de aves adaptado com efluente de bovinocultura, que a maior parte das estruturas celulares se encontravam danificadas e, possivelmente, comprometidas. 

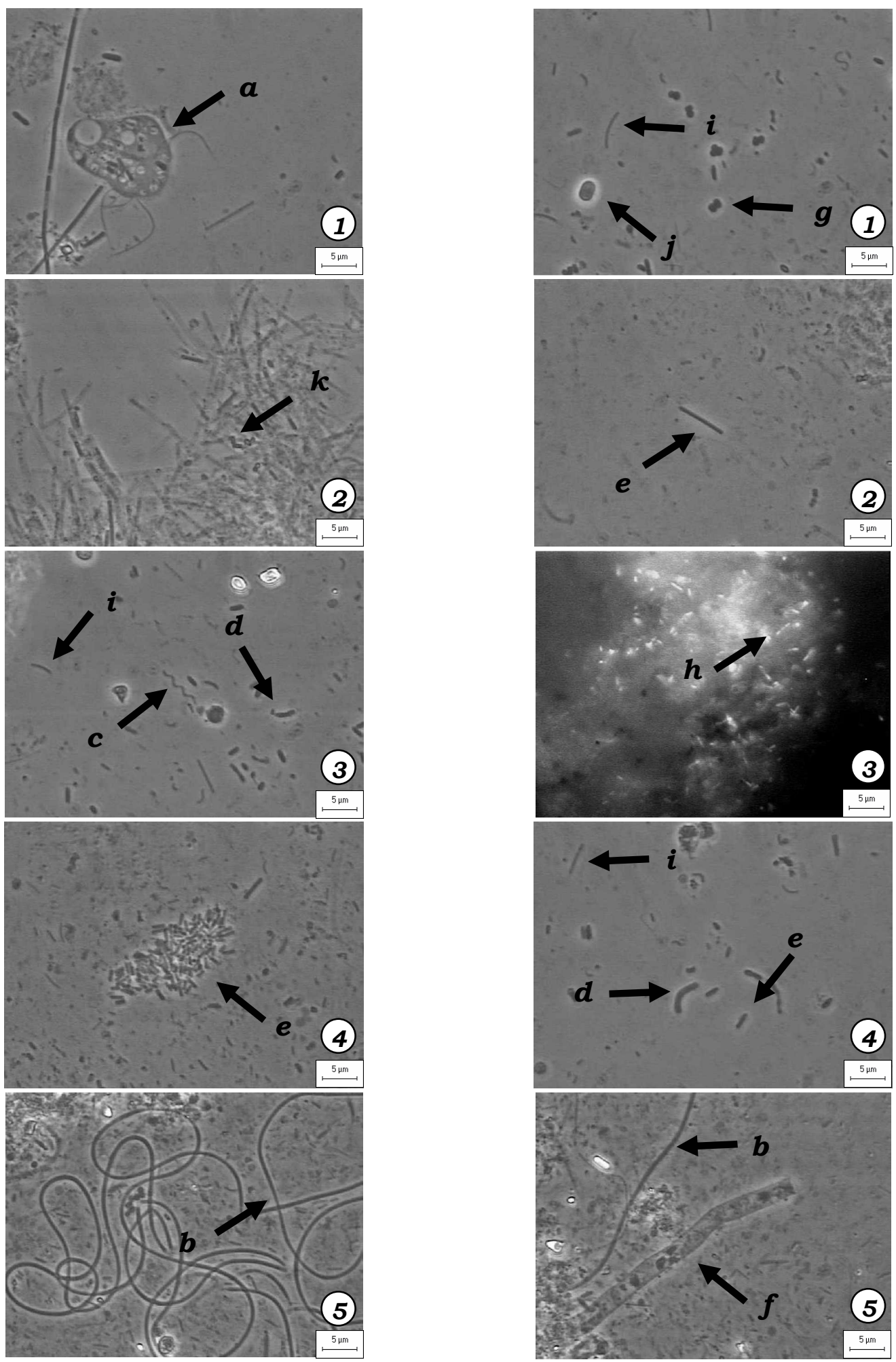

FIGURA 4. Espécies microbianas observadas: $\boldsymbol{a}$-protozoário flagelado; $\boldsymbol{b}$-célula semelhante a Methanotrix sp; $\boldsymbol{c}$ - espirillum sp; $\boldsymbol{d}$ - bacilo curvo; $\boldsymbol{e}$ - bacilo reto; $\boldsymbol{f}$ - fungo filamentoso; $\boldsymbol{g}$ - $\operatorname{cocos} \mathrm{sp} ; \boldsymbol{h}$ - bacilo fluorescente; $\boldsymbol{i}$ - bacilo fino; $\boldsymbol{j}$ - cocos bacilos; $\boldsymbol{k}$ - microrganismos com estruturas celulares danificadas. Nos lodos: $\mathbf{1}$ - abatedouro de aves não-adaptado; $\mathbf{2}$ abatedouro de aves adaptado com substrato de bovinocultura; 3 - abatedouro de aves adaptado com substrato de suinocultura; $\boldsymbol{4}$ - bovinocultura; 5 - suinocultura (objetiva 100, ocular 10 e zoom 1,25). 
Provavelmente, a DQO inicial do substrato de bovinocultura utilizado na adaptação do lodo de abatedouro de aves foi insuficiente para a manutenção de espécies bacterianas necessárias à digestão anaeróbia, e mesmo após as adições diárias de substrato, que gradualmente aumentaram a DQO do meio, não houve recuperação dessas espécies.

\section{CONCLUSÕES}

A avaliação da biodegradabilidade anaeróbia de dejetos provenientes de diferentes atividades zootécnicas pode ser realizada por testes simplificados de bancada por meio do monitoramento da DQO ao longo do tempo e da estimativa da taxa de utilização de substrato, permitindo, dessa forma, agregar conhecimentos ao processo de biodegradação desses resíduos.

Os resultados obtidos nos ensaios do efluente de bovinocultura, com lodo de abatedouro de aves não-adaptado $\left(\mathrm{k}_{1}=2,51 \times 10^{-2} \mathrm{~h}^{-1}\right)$, e com lodo de bovinocultura $\left(\mathrm{k}_{1}=2,54 \times 10^{-2} \mathrm{~h}^{-1}\right)$, indicaram grande semelhança no processo de biodegradação desse substrato, pelos dois tipos de biomassa, conforme indicam os valores de $\mathrm{k}_{1}$ estimados.

A máxima biodegradabilidade foi observada no ensaio realizado com efluente de suinocultura, degradado por lodo de suinocultura $\left(\mathrm{k}_{1}=4,09 \times 10^{-2} \mathrm{~h}^{-1}\right)$.

\section{AGRADECIMENTOS}

À Fundação de Amparo à Pesquisa do Estado de São Paulo - FAPESP, pelo financiamento da pesquisa, e ao Conselho Nacional de Desenvolvimento Científico e Tecnológico - CNPq, pela bolsa de estudos concedida ao primeiro autor.

\section{REFERÊNCIAS BIBLIOGRÁFICAS}

AWWA/APHA, WEF. Standard methods for the examination of water and wastewater. 20.ed. Washington, 1998. $1.325 \mathrm{p}$.

BUENO, C.F.H. Produção e manejo de esterco. Informe Agropecuário, Belo Horizonte, v.12, n.135/136, p.81-5, 1986.

DILLALO R.; ALBERTSON O.E. Volatile acids by direct titration. Journal Water Pollution Control Federation, Alexandria, v.33, n.4, p.356-65, 1961.

IBGE - FUNDAÇÃO INSTITUTO BRASILEIRO DE GEOGRAFIA E ESTATÍSTICA. Censo Agropecuário (1996). Disponível em: <http:// www.sidra.ibge.gov.br/bda/tabela/listabl.asp?c=325>. Acesso em: 28 novembro 1997.

KONZEN, E.A. Manejo e utilização de dejetos de suínos. Concórdia: EMBRAPA-CNPSA, 1983. 32 p. (Circular Técnica, 6)

MORAES, L.M. Avaliação da biodegradabilidade anaeróbia de dejetos oriundos de atividades zootécnicas. 2000. 121 f. Dissertação (Mestrado em Água e Solo) - Faculdade de Engenharia Agrícola, Universidade Estadual de Campinas, Campinas, 2000.

PAULA JÚNIOR, D.R. Processos anaeróbios de tratamento: fundamento e aplicações. In:

SEMINÁRIO DE HIDRÓLISE ENZIMÁTICA DE BIOMASSA, 4., 1994, Maringá. Anais... Maringá: Editora da Universidade de Maringá, 1995. p.127-40.

RIPLEY L.E.; BOYLE W.C.; CONVERSE J.C. Improved alkalimetric monitoring for anaerobic digestion of high-strength wastes. Journal Water Pollution Control Federation, Alexandria, v.58, n.5, p.406-11, 1986. 
SILVEIRA, B.I. da. Cinética química das reações homogêneas. Curitiba: Edgard Blücher, 1989.172 p.

VIEIRA, L.G.T.; ZAIAT, M.; FORESTI, E.; HOKKA, C.O. Estimation of intrinsic kinetic parameters in immobilized cell systems for anaerobic wastewater treatment. Biotechnology Techniques, Surrey, v.10, p.635-8, 1996.

WOLTERS, G.M.V.H.; BOEREKAMP, J.A.M. Reduction of wastewater from cleaning of milking equipment. In: INTERNATIONAL DAIRY HOUSING CONFERENCE, 3., 1994, Orlando. Proceedings... Orlando: American Society of Agricultural Engineers, 1994. p.700-3.

ZHANG, R.H.; DAGUE, R.R. Treatment of swine wastes by the anaerobic sequencing batch reactors system. In: INTERNACIONAL SYMPOSIUM ON AGRICULTURAL AND FOOD PROCESSING WASTES, 7., 1995, Chicago. Proceedings... Chicago: American Society of Agricultural Engineers, 1995, p.301-8. 